\title{
Assessing Work Zone Traffic Control Options for 3-to-1 Lane Closures
}

\author{
Troyee Saha, Virginia P. Sisiopiku \\ Department of Civil, Construction, and Environmental Engineering, University of Alabama at Birmingham, Birmingham, AL, \\ USA \\ Email: vsisiopi@uab.edu
}

How to cite this paper: Saha, T. and Sisiopiku, V.P. (2020) Assessing Work Zone Traffic Control Options for 3-to-1 Lane Closures. Journal of Transportation Technologies, 10, 50-64.

https://doi.org/10.4236/jtts.2020.101004

Received: December 7, 2019

Accepted: January 10, 2020

Published: January 13, 2020

Copyright (c) 2020 by author(s) and Scientific Research Publishing Inc. This work is licensed under the Creative Commons Attribution International License (CC BY 4.0).

http://creativecommons.org/licenses/by/4.0/

(c) (i) Open Access

\begin{abstract}
The presence of highway construction zones hinders mobility and affects traffic operations. A 2002 study by Wunderlich \& Hardesty reported that nearly $20 \%$ of the National Highway System roads have scheduled construction work during the peak construction season. Additionally, approximately $24 \%$ of non-recurring delays on freeways are caused by work zones. To minimize time lost by travelers due to work zone induced traffic congestion, it is important to efficiently plan temporary traffic control (TTC) at work zones. Earlier research conducted by Sisiopiku \& Ramadan, 2017 confirms that the majority of State Departments of Transportation currently rely on their earlier experience when planning for work zones, rather than consider operational and safety impacts. Using a study corridor in Birmingham, Alabama as a test bed, this study investigated the operational impacts of TTC options for work zones with 3-to-1 lane drop configuration using traffic data collected from the Alabama Department of Transportation. The VISSIM simulation platform was used to conduct the experiments. The experimental design considered two TTC strategies (i.e., static late and early merge) under 3-to-1 lane drop configuration for work-space length of $500 \mathrm{ft}$ for long- and short-term lane closures. The study concluded that the 3-to-1 lane-drop configuration should not be scheduled for long-term duration. Maintenance work can be scheduled from midnight to early morning and under the 3-to-1 lane closure scenario the performance of early and late merge traffic control is similar. Overall, this study used simulation modeling to compare the effectiveness of two traffic control strategies at work zones on the basis of different performance measures. The results provide information about the impact of each control strategy on density, speed, travel time etc. They also help determine what time of the day is best for lane closings in order to reduce adverse impacts from capacity reduction. Thus, the findings are expected to provide valuable guidance for agencies responsible for planning, design, and operations of work zones in the future.
\end{abstract}




\section{Keywords}

Work Zone Traffic Control, Early Merge, Late Merge, VISSIM, Simulation

\section{Introduction}

Maintenance and rehabilitation work are very important for proper functioning of roadways. Several states opt for construction work on the existing roadways to improve roadway condition and serve the traveling public. Often, lane closures are required whenever there is an active work zone. In fact, nearly $20 \%$ of the US National Highway System roads have construction work during the peak construction season [1] and there is a possibility that a driver would confront one active work zone out of every hundred miles driven on the highway [2]. Work zones reduce the capacity of roadways and affect traffic flow at merge points [3]. During the uncongested situation, vehicles can drive at regular speed, but speeds may decline by $31.6 \%$ to $56.1 \%$ of the regular speed at work zones [4].

Researchers estimate that work zones cause approximately $24 \%$ of non-recurring delays [5] and not only affect mobility of travelers going through the construction zone, but also negatively impact local businesses and nearby communities. Studies indicate that the total cost of traffic congestion resulting from travel delay and extra fuel cost was $\$ 115$ billion in 2009 [6]. They also estimate the total travel delay cost for a hypothetical 2-mile work zone at $\$ 196,342 /$ day, assuming 6-lane interstate and $88 \%$ passenger cars in the regular traffic flow. Proper design, traffic control, and scheduling of work zones can minimize the adverse impacts of work zones on traffic operations and benefit the traveling public.

One strategy used to manage traffic through work zone lane closures is conventional Temporary Traffic Control (TTC). TTC methods can be static or dynamic. The choice depends on the time period of work zone presence, traffic volume, driving behavior, etc. Selection of TTC should be based on evaluation of operational impacts of the specific strategy at specific work zone and safety considerations. Some strategies perform well when traffic demand is low but may not be efficient when volume exceeds capacity. The situation becomes even worse when queues extend upstream beyond the warning signs, in which case congestion becomes severe and the possibility of collision increases [7].

Given the time and money lost by travelers due to work zone induced traffic congestion, it is important to efficiently plan temporary traffic control at work zones. In fact, the Federal Highway Administration (FHWA) has developed a rule according to which all state and local highway organizations should have guidelines for evaluating mobility impacts and managing safety at work zone locations for each project [6] [8]. Currently, many state Departments of Transportation (DOT) consider user delay as a measure of mobility [8]. To 
reduce impacts on traffic operation and safety, many agencies limit the scheduling of work zone lane closures during off-peak hours. However, this strategy results in increased project duration while setup-related time and cost also increase [9].

Lane closures at work zones may take place for pavement repair, resurfacing, installation of pavement markers, asphalt removal, etc. Hence, planning of work zone traffic control should be done cautiously so that lane closures have minimum impacts on operations [10]. However, earlier research confirms that the majority of State DOTs do not have formal guidelines for selecting TTC strategy for work zones; instead, they rely on their earlier experience without consideration of operational nor safety impacts [11].

Some earlier studies looked at TTC strategies for short-term work zones under a 3-to-2 lane drop scenario. However, very few studies focused on assessing the impact of TTC strategies for 3-to-1 lane configuration and no study focused on long-term work zone for 3-to-1 lane closure. Therefore, there is a need to study different TTC strategies for long-term and short-term work zones for 3-to-1 lane closure configuration so that transportation agencies can make informed decisions when trying to optimize traffic flow and minimize delays at work zone under the 3-to-1 lane closure scenario. The objective of the study is to investigate the operational impacts of two TTC strategies for work zones, namely static late- and early merge control with 3-to-1 lane-drop configuration under varying traffic demand conditions.

\section{Significance and Implications of the Study}

The research bridges the gap between construction work scheduling and transportation planning research. Earlier simulation studies concentrating on static early- and late merge mostly considered short-term work zones during off-peak [12] [13] [14]. Additionally, research and analysis of the 3-to-1 lane closure configuration is very limited. Therefore, this study contributes to better understanding of work zone operation under constrained roadway capacity (i.e., 3-to-1 lane closure configuration). The study findings are expected to provide valuable guidance for agencies responsible for planning, design, and operations of work zones and help them to better plan future work zones, particularly those involving partial closures on freeways.

\section{Literature Review}

Various State DOTs implement merge control strategies at work zones according to the procedures described in the Manual of Uniform Traffic Control Devices (MUTCD) [15]. The literature review reveals that TTC methods used in practice include static early and late merge [16] [17], dynamic early merge or dynamic late (zipper) merge [18], reduced speed when flashing [19], and closure of entrance ramps during construction [20]. The main features of commonly used TTC methods are discussed next. 


\subsection{Static or Dynamic Early Merge}

Static early merge technique is employed by placing lane closing signs a few miles ahead of the actual closed lane at one-mile intervals. This set up gives drivers that are approaching a work zone advanced information about which lane is closed and enough time to merge in the open lane(s). Since advanced warning is placed well upstream of closed lanes, early merge can also decrease the probability of rear-end collision occurrence [18]. Static early merge control increases the number of free merges and when this is incorporated with effective warning distance of 1-mile, the percentage of free merges becomes greater than or equal to 90 [21]. However, early studies report that congestion may occur in the open lane(s) since many drivers merge very early, thus abandoning their lane for a distance more than required, a practice that leads to higher delays and travel time [22]. It has also been reported that drivers face confusion about the instructions to merge early in low-volume situations [23]. Another disadvantage is that maintenance of signage and other control measures becomes difficult [24].

Dynamic early merge technique incorporates real time traffic information in warning signs, thus the distance of warning from the closed lane varies according to the traffic demand level. Field tests in Indiana and elsewhere confirmed smoother lane merging with dynamic early merge control than with the conventional method [16] [18]. However, several studies revealed that capacity reduces by using this type of traffic control, thus travel times increase, and long queues develop during high demand volume [25].

\subsection{Static or Dynamic Late (Zipper) Merge}

Static late merge is a strategy under which drivers remain in their respective lanes up to a certain merge point closer to the lane closure and then enter into the open lane in a zipper fashion, hence it is called "zipper merge" as well. Contrary to early merge, drivers do not merge into open lane much in advance of the lane closure and do not need to worry about which lane is closed ahead of time, since all lanes can be used before the merge point. The Minnesota Department of Transportation (MnDOT) has evaluated this strategy and concluded that queue length can be reduced by $40 \%$ by implementing late merge control [17]. The superiority of late merge TTC at 3-to-2 lane closures was further confirmed by Ramadan and Sisiopiku in 2018 [20].

The dynamic late merge (DLM) strategy attempts to address the problems associated with static late merge during high-speed and low traffic volumes conditions. So, dynamic late merge considers real-time information of traffic and accordingly changes merge points and controls the traffic in a fashion similar to early merge control during off-peak. To ensure effective use of dynamic late merge, volume and speed threshold points need to be identified for interchanging between early and late merge control [18].

Table 1 presents a summary of available strategies focusing on their potential benefits and limitations as reported in the literature. 
Table 1. Summarizing the findings of different traffic control options.

\begin{tabular}{lll}
\hline $\begin{array}{l}\text { Type of the traffic } \\
\text { control strategy }\end{array}$ & Potential benefits & Limitations \\
\hline Static Early Merge & $\begin{array}{l}\text { Reduces merge related collisions, } \\
\text { rear-end collisions; Increases free } \\
\text { merges at higher traffic volume }\end{array}$ & $\begin{array}{l}\text { Congestion, Lane-change crashes; } \\
\text { Difficult maintenance of signage }\end{array}$ \\
$\begin{array}{ll}\text { Dynamic Early } \\
\text { Merge }\end{array}$ & $\begin{array}{l}\text { Provides varying no-passing zone } \\
\text { based on detectors; Smooth merging }\end{array}$ & $\begin{array}{l}\text { Ineffective for queues beyond the } \\
\text { detectors; Results in higher travel time }\end{array}$ \\
Static Late Merge & $\begin{array}{l}\text { Reduces queue length and rear-end } \\
\text { crashes }\end{array}$ & $\begin{array}{l}\text { Safety issues in low-volume and } \\
\text { high-speed situations }\end{array}$ \\
Dynamic Late & $\begin{array}{l}\text { Changeable merge point is based on } \\
\text { real-time information }\end{array}$ & $\begin{array}{l}\text { Threshold volume and speed needs to } \\
\text { be evaluated accurately }\end{array}$ \\
\hline
\end{tabular}

\subsection{Current State-of-Practice in the United States}

A detailed study about the current practice to control traffic at work zones around the states had been conducted by questionnaire survey among DOTs [25]. The study gathered information from 27 states over a period at more than one month. The response from these states about the merge control strategy used during work zone lane closures identified that most of them follow merge control strategies based on their previous experience [26]. Another study indicated that the majority of states carry on the work during night time or off-peak based on the type of roadway [27].

Several studies have examined TTC strategies for work zones around the states. Some conducted field tests and some used simulation studies to evaluate the performance of different TTCs. Earlier studies and their findings are important for enabling efficient work zone planning. Table 2 summarizes earlier studies that are conducted by researchers focusing on different temporary traffic controls and highlights major findings.

A wide variety of microscopic simulation tools are available and can be used to analyze traffic impacts on work zones. Based on the literature, VISSIM was selected as the simulation platform in this study for its superiority and ability to meet the study goals and needs.

\section{Methodology}

The purpose of the study is to investigate operational performance of early- and late merge TTC for 3-to-1 lane closure configuration for various work zone lengths using simulation modeling. In this study, a 12-mile corridor of Interstate 65 (I-65), passing through the city of Birmingham in the state of Alabama, was selected as the test bed. The study corridor extends from downstream of Exit 247 near Valleydale Road to just before Exit 261A on the northbound direction where the interstate passes over 1st Ave North. The interstate has 3 traffic lanes per direction, with occasional acceleration/ deceleration lanes added near ramps to facilitate the vehicle movements. The typical lane width is $12 \mathrm{ft}$ and the posted speed limit is $60 \mathrm{mph}$ on the interstate and $45 \mathrm{mph}$ on the ramps. 
Table 2. Summary of earlier studies on various temporary traffic control (TTC) strategies.

\begin{tabular}{|c|c|c|c|c|c|}
\hline Study & yStrategy & Period & $\begin{array}{l}\text { Lane closure } \\
\text { configuration }\end{array}$ & $\begin{array}{l}\text { Approach of } \\
\text { analysis }\end{array}$ & Findings \\
\hline [28] & $\begin{array}{l}\text { Static Late merge } \\
\text { vs early merge }\end{array}$ & Short-term & $\begin{array}{l}\text { 2-to-1, 3-to-1, } \\
\text { and 3-to-2 }\end{array}$ & $\begin{array}{l}\text { Microscopic } \\
\text { simulation }\end{array}$ & Late merge is better \\
\hline [12] & $\begin{array}{l}\text { Static Late merge, } \\
\text { early merge, } \\
\text { signalized merge }\end{array}$ & Short-term & $\begin{array}{l}\text { 2-to-1, 3-to-1, } \\
\text { and 3-to-2 }\end{array}$ & $\begin{array}{l}\text { Microscopic } \\
\text { simulation }\end{array}$ & $\begin{array}{l}\text { Late merge is better for } \\
\text { high volumes, Early merge } \\
\text { is better for low volume }\end{array}$ \\
\hline $\begin{array}{l}\text { [13], } \\
{[14]}\end{array}$ & $\begin{array}{l}\text { Conventional } \\
\text { practice, Dynamic } \\
\text { early and Dynamic } \\
\text { late }\end{array}$ & Short-term & 2-to-1, 3-to-2 & $\begin{array}{l}\text { Microscopic } \\
\text { simulation }\end{array}$ & $\begin{array}{l}\text { Dynamic early merge is } \\
\text { better }\end{array}$ \\
\hline [29] & Zipper merge & $\begin{array}{l}\text { Congested } \\
\text { time period } \\
\text { at field site }\end{array}$ & 2-to-1, 3-to-2 & $\begin{array}{l}\text { Field test on } \\
\text { Freeways, } \\
\text { arterials }\end{array}$ & $\begin{array}{l}\text { Increased safety, reduced } \\
\text { travel time }\end{array}$ \\
\hline [30] & $\begin{array}{l}\text { Dynamic Late } \\
\text { merge }\end{array}$ & Field site & 2 -to-1 & $\begin{array}{l}\text { Microscopic } \\
\text { simulation }\end{array}$ & $\begin{array}{l}\text { Dynamic late merge is } \\
\text { better than conventional }\end{array}$ \\
\hline [31] & $\begin{array}{l}\text { Dynamic Late } \\
\text { merge }\end{array}$ & Field site & 2 -to-1 & $\begin{array}{l}\text { Field test on } \\
\text { Freeways }\end{array}$ & $\begin{array}{l}\text { Reduced travel time; } \\
\text { better than early merge }\end{array}$ \\
\hline
\end{tabular}

Traffic volumes for the study corridor mainline were obtained through the Alabama Department of Transportation (ALDOT) for Thursday April 19, 2018, a typical weekday. The volumes were obtained for $24 \mathrm{hrs}$ on an hour-by-hour basis starting from 12 midnight. The Traffic Monitoring section of the Maintenance Bureau at ALDOT routinely collects and maintains traffic volume for the major roadways in the state of Alabama. For traffic coding purposes, in addition to mainline counts, on-ramp and off-ramp volumes were also needed. Those are collected periodically by ALDOT and were obtained by contacting with the personnel of ALDOT. Many of those ramp counts were not collected on April 19, 2018 but all were collected in 2018 . Traffic volumes were balanced to ensure that no vehicles were disappearing from the network. Heavy vehicles accounted for $10 \%$ of the total volume.

For network coding, the roadway network geometry was obtained from available aerial map of VISSIM. Moreover, the number of lanes, location of auxiliary lanes, and curves were confirmed by field visits. All segments of study corridor were drawn using links and the connector feature of VISSIM. One link can have the same number of lanes throughout it. Therefore, separate links were drawn from one exit to the next one since the total number of lanes remains same for such segments except for locations where auxiliary lanes are needed. The width of each lane was set to be $12 \mathrm{ft}$. On-ramp and off-ramp segments were drawn using the link feature. To represent extra lanes for deceleration, a connector was drawn starting from the end of freeway link end extending until the starting point of off-ramp link. Acceleration lanes were also coded in a similar manner.

Traffic coding was used to input traffic volume with correct vehicle composition for each link. Traffic demand data set was prepared based on field observed data retrieved from ALDOT data sources. In VISSIM, traffic can enter at the 
starting point of a link. To represent actual conditions, vehicles' entrance was coded for the very first link of interstate and for the entrance at each on-ramps. The data sheet was prepared for on-ramp volumes so that the mainline volume for all links matches with actual data. Vehicles exit behavior also needed careful coding as VISSIM has various route choice decisions. Vehicle routes have a sequence of links and connectors that direct vehicles in the desired direction. For this study, the static route decision was coded before each exit. One route directed vehicle towards the off-ramp, and another route directed vehicle along the interstate. Based on ALDOT's off-ramp data, exit volumes were coded using route choice decision and the rest were entered in the straight direction of the route to make sure that no vehicles were disappearing or added automatically in the network.

Once the geometric properties of the study corridor and traffic data were established, simulation models were developed in VISSIM for baseline conditions (i.e., no work zone presence) and for work zone operation with a 3-to-1 lane closure configuration. A work zone length of $500 \mathrm{ft}$ was considered for long-term work zone operation ( $24 \mathrm{hrs)}$ ), as well as for short-term work zone operation during the 3-hr morning peak hour (6:00-9:00 AM) and 3-hr non-peak period (9:00 PM-midnight). Based on the findings from the $500 \mathrm{ft}$ work zone length, other work zone lengths were tested for peak and non-peak short-term work zones (i.e., $1000 \mathrm{ft}$ and $1500 \mathrm{ft}$ ).

Five iterations were performed for each simulation scenario tested and the results were averaged. To allow for comparisons, the same five random seeds were maintained for all versions of models (one for each iteration) to ensure that no change in the results was attributable to the vehicle arrival patterns. In addition to the seed numbers, parameters such as warm-up period, simulation resolution, and other model assumptions were kept the same throughout the simulation process.

After coding the network and traffic in the VISSIM model, effort was made for calibration and validation of the model. The goal of the calibration and validation effort was to fine-tune the model so that travel time from VISSIM for each hour falls within $\pm 15 \%$ range of field travel time values. The field travel times were obtained from the National Performance Management Research Data Set (NPMRDS) through the Regional Planning Commission of Greater Birmingham (RPC). The plot depicted in Figure 1 shows the comparison between the actual travel time from the NPMRDS dataset (RPC data) and the travel times obtained from the VISSIM base model. The plot shows the upper control limit (UCL) and the lower control limit (LCL) which represent a 15\% increase and a $15 \%$ decrease of RPC data respectively.

As shown in Figure 1, the line that represents the VISSIM model's travel time along the study corridor nicely matches the field data and falls within the upper limit and lower limit boundaries. The validation effort undertaken in this study ensured that the model represents the actual traffic behavior observed on the selected study segment. 


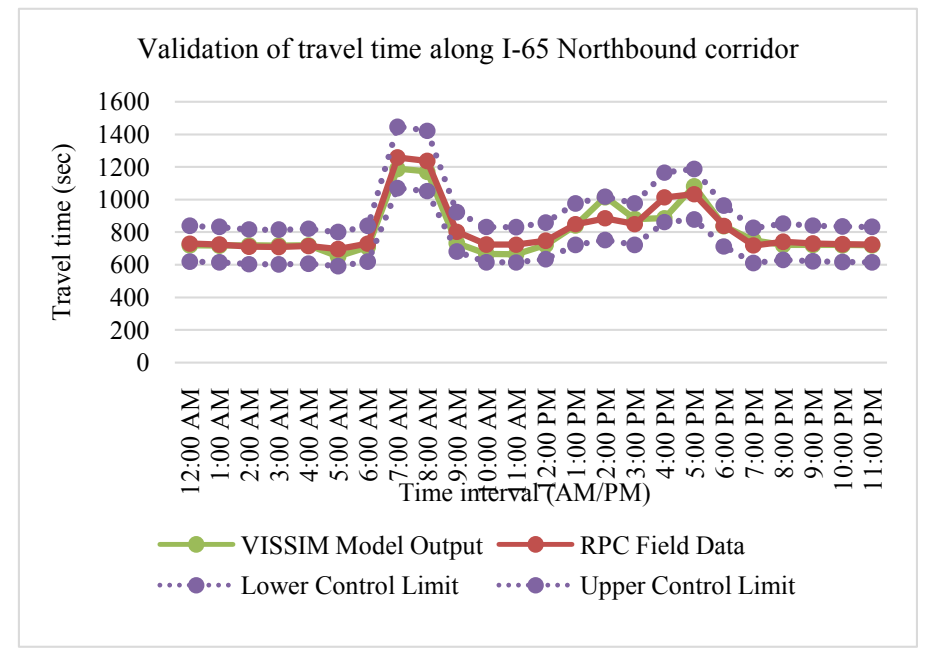

Figure 1. Validation of travel time along northbound corridor.

\section{Work Zone Setup}

Once the base model was calibrated and validated, a work zone was placed in the middle portion of the study corridor in the northbound direction. The 3-to-1 lane closure configuration closed the two right most lanes, leaving the left-most lane in operation through the work zone. Early merge- and late merge traffic control were coded in VISSIM using link structures and connectors, along with route decisions. According to the experimental design of the study, a short work zone length was considered equal to $500 \mathrm{ft}$. Initially, both early merge and late merge scenarios were coded for long-term work zones, meaning the work zone was active on the roadway segment for a 24 -hr period. Then, based on the findings from long-term work zone study, separate models of peak and non-peak hour were also considered.

Traffic density, speed, travel time, and flow were selected as measures of effectiveness (MOE). Results comparing density and speed are shown in this paper. Detailed results can be found in the original research work [32]. The MOEs used in the analysis were extracted for the study segments located upstream of the starting point of the work zone, the segment including the work area, and the segment 1 mile downstream of the work zone end. Flow and density obtained under the 3-to1 lane closure operation were estimated per lane and then compared against base model outputs.

\section{Data Analysis and Results}

\subsection{Long-Term Work Zone Analysis (24 hr) for $500 \mathrm{ft}$ Work Zone}

The simulation models of early and late merge scenarios with a $500 \mathrm{ft}$ 3-tol work zone closure were run for a 24 -hr period. Figure 2 shows the flow along the segments from the start of the study corridor (i.e., upstream of the work zone) and up to one mile downstream of the work zone (a total of 7.61 mile from exit 247 to exit 255). 


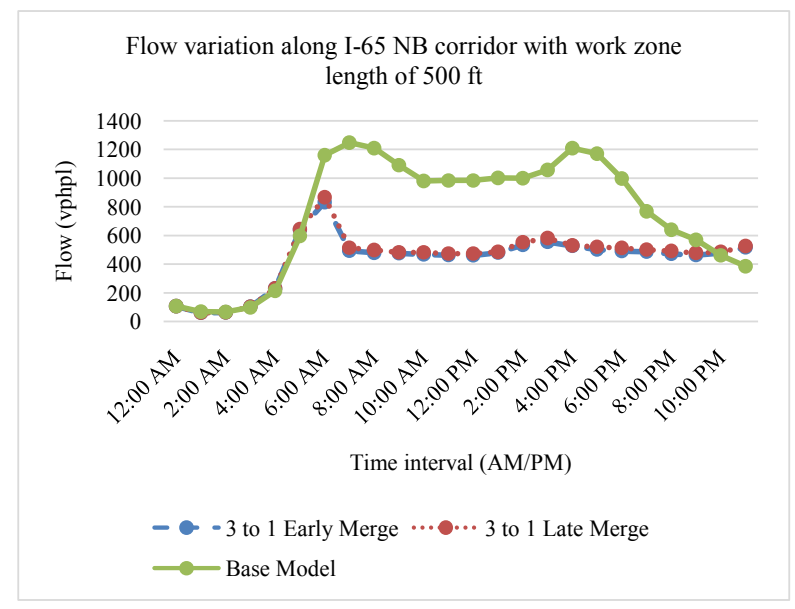

Figure 2. Flow variation along I-65 NB corridor (work zone length of $500 \mathrm{ft}$ ).

The results show that when the volume was far below the capacity (for instance at midnight), the presence of the work zone did not have much impact on the flow. However, when the volume started to increase from 6:00 AM in the morning, the work zone scenario quickly resulted in oversaturated conditions, leading to sever congestion. This was the case for both TTC options considered. One noteworthy observation is that the system became completely overwhelmed by the 2-lane closure and could not recover throughout the day. This is because the capacity of one open lane is not enough to handle the demand and cannot clear the traffic accumulated from previous time intervals. Therefore, congestion persists even in the non-peak hours.

\subsection{Short-Term Work Zone Analysis (Peak Period) for $500 \mathrm{ft}$ Work Zone}

Besides the investigation of the impact of a long-term work zone with two lanes closing, the researchers also looked at the impact of a 3-to-1 closures for short-term work zones. Short-term work zones were analyzed for the morning peak period (6:00 AM to 9:00 AM) which is the most severe peak period along the northbound direction. The VISSIM model was run for AM peak period and generated MOEs such as hourly flow, speed, density, and travel time for base scenario (without any work zone), and for the 3-to-1 early and late merge scenarios. Then each MOE was compared for all these three situations for a specific time. Sample results showing density and speed are depicted in Figure 3 and Figure 4, respectively.

As expected, the base model outperformed the short-term 3-to-1 work zone lane closure of $500 \mathrm{ft}$ length during the AM peak with respect to density and speed. When early merge and late merge performance were compared, it was observed that late merge resulted in slightly better performance than early merge for all MOEs considered as long as the volume-to-capacity ratio was under 1 . However, under oversaturated conditions both types of merge controls failed to accommodate the demand. 


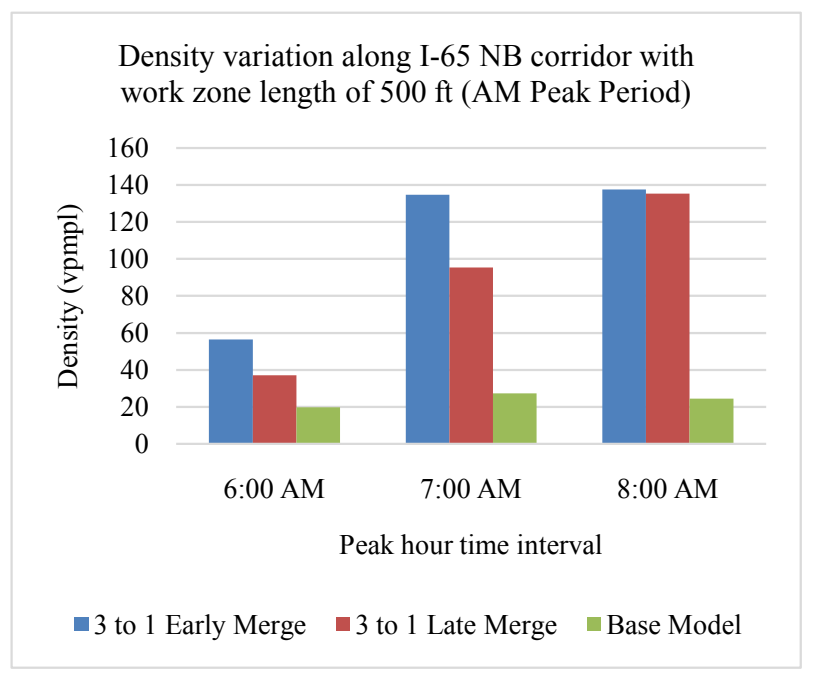

Figure 3. Density variation along I-65 NB corridor (work zone length of $500 \mathrm{ft}$, AM Peak period).

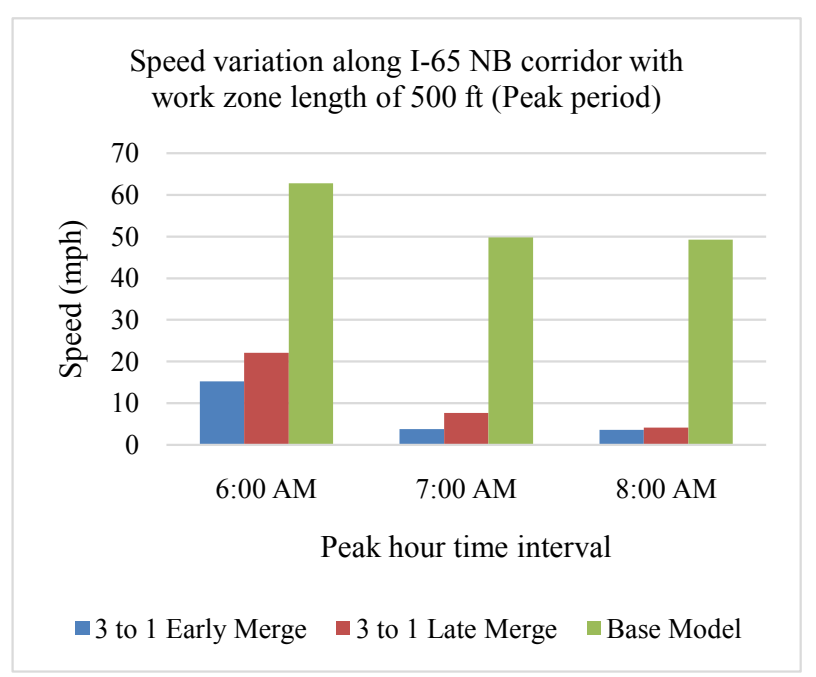

Figure 4. Speed variation along I-65 NB corridor (work zone length of $500 \mathrm{ft}$, AM Peak period).

\subsection{Short-Term Work Zone Analysis (Non-Peak Period) for $500 \mathrm{ft}$ Work Zone}

Since late merge strategy performs slightly better than early merge at the onset of the peak hour, it is important to examine if the same is true for non-peak hours or not. Therefore, MOEs were collected for a non-peak time interval (9:00 PM-12:00 AM) and compared, as shown in Figure 5 and Figure 6.

As far as the throughput is concerned all options perform similarly during the night non-peak time period. Given the low demand during the 9:00 PM-12:00 AM time period (i.e., low volume-to-capacity ratio) the performance of the network is not affected by the 3-to-1 lane closure and the remaining open lane can handle the traffic demand at that time. This observation is consistent in the results presented in Figure 5 through Figure 6 and all other MOEs considered in 
the study. Moreover, late merge control options show a small advantage over early merge control, but it is not clear from the direct comparison if this is significant enough to justify its selection over its counterpart.

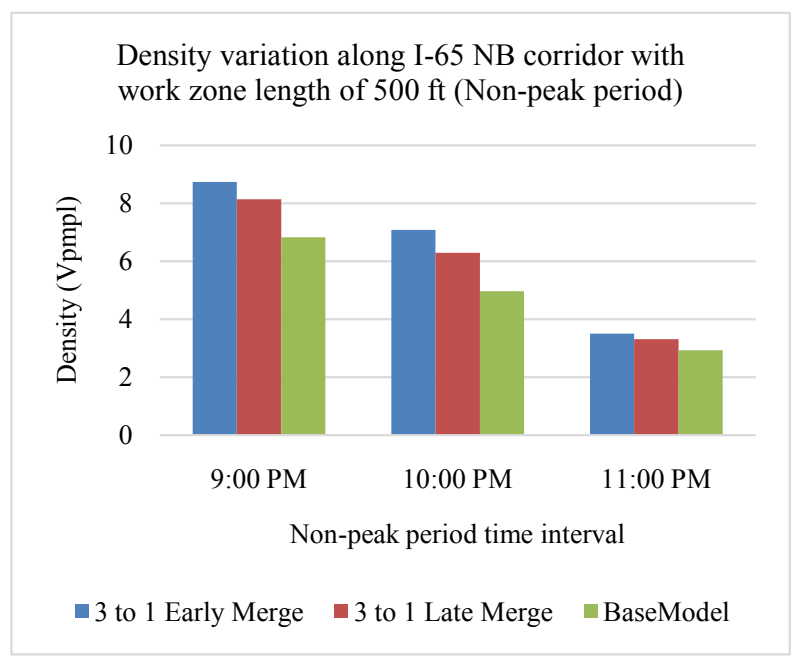

Figure 5. Density variation along I-65 NB corridor (work zone length of $500 \mathrm{ft}$, Non-peak period).

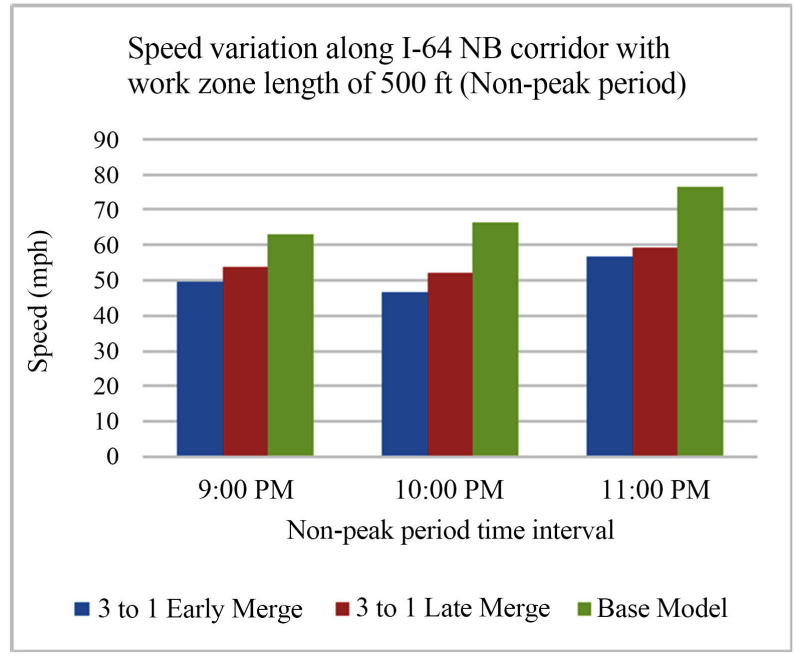

Figure 6. Speed variation along I-65 NB corridor (work zone length of $500 \mathrm{ft}$, Non-peak period).

\subsection{Statistical Analysis}

The comparisons performed so far focused on visual inspections of MOEs estimated values. Still, there is a need to study if the observed difference in the performance between early- and late merge traffic control is statistically significant. Therefore, a t-test was conducted to identify the t-score for each of the MOEs considered in comparisons. The $\mathrm{t}$-score has to be more than 2.132 to ensure with $90 \%$ confidence that the MOEs are significantly different between early and late merge for two-tailed test. Two-tailed test means that one set of values can be significantly greater or smaller than another set of values. 
The results from the comparison based on a two-tailed t-test and for a $90 \%$ confidence interval are shown in Table 3 . All t-test scores are found to be below 2.132, which confirms that for 3-to-1 lane closures, early merge and late merge traffic control strategies do not have statistically significant differences in their performance. In other words, any of these two TTC strategies will result in similar impacts in the presence of a 3-to-1 lane closure for work zone length of $500 \mathrm{ft}$ under both peak and non-peak traffic conditions.

Table 3. T-score for statistical significance analysis.

\begin{tabular}{ccccc}
\hline Length & Time period of day & MOEs & T-score (Two-tailed test) & Significance \\
\hline \multirow{2}{*}{$500 \mathrm{ft}$} & Peak & Density & 0.20024 & Not significant \\
& & Speed & 0.17525 & Not significant \\
& \multirow{2}{*}{ Non-Peak } & Density & 0.10013 & Not significant \\
& & Speed & 0.03693 & Not significant \\
\hline
\end{tabular}

\section{Conclusions and Recommendations}

This study investigated the operational impacts of two temporary traffic control (TTC) strategies, namely static late and early merge control with 3-to-1 lane-drop configurations for a hypothetical work zone at a corridor along I-65 in Birmingham, AL. Some major findings from this study are summarized below:

- Between 12:00 PM and 5:00 AM, a time period that corresponds to very low demand, 3-to-1 lane closures are feasible under any type of traffic control configuration studied.

- During the morning peak, the 3-to-1 lane closure results in rapid deterioration of traffic conditions. The corridor becomes overwhelmed by the excess demand and unable to cope.

- When considering short-term work zones during the morning peak, the late merge strategy slightly outperforms the early merge one, when volume-to-capacity ratio is still below 1 .

- Late merge and early merge traffic control for a 3-to-1 lane drop scenario perform quite similarly during the non-peak period with short-term work zones.

- While late merge control outperforms early merge control when any noticeable differences between the two strategies are observed, the differences are not statistically significant for any of the comparisons performed in this study.

Based on the findings from this investigation, it is recommended that long-term work zones with 3-to-1 lane closures should be avoided. Instead, short duration closures should be considered, preferably during non-peak periods in order to minimize the impacts on traffic operations.

\section{Suggestions for Future Study}

This study did not consider traffic diversion during the 3-to-1 lane closures at the worksite. As a result, the traffic network quickly became oversaturated and 
failed to serve the demand. A sensitivity analysis is recommended to determine the percentage of traffic that needs to be diverted in order to provide an acceptable level of service to users of the facility during the 3-to-1 operation. Moreover, work zone capacity can be determined by using machine learning method [33] as this technique is robust and can handle a large number of variables [34]. Future study can also look into the impact of 3-to-1 lane closure at work zones during other time intervals and at roadway facilities with different design configurations. Also, the impact of placement of the lane closures on the left side, rather than the right should be further investigated in follow up studies.

\section{Acknowledgements}

The study is sponsored by research grants provided by the Southeastern Transportation, Research, Innovation, Development and Education (STRIDE) Center and the Alabama Department of Transportation (ALDOT). The authors wish to thank the RPC for making available travel time data from the National Performance Management Research Data Set (NPMRDS) and Drs. Ossama Ramadan and Rod Turochy for their valuable assistance with this study.

\section{Conflicts of Interest}

The authors declare no conflicts of interest regarding the publication of this paper.

\section{References}

[1] Wunderlich, K. and Hardesty, D. (2002) A Snapshot of Work Zone Activity Reported on State Road Closure and Construction Websites. Mitretek Systems, Falls Church.

[2] Wolff, G. (2007) Traffic Control Safety: Meeting the FHWA Minimums Is Not Enough. In: ASSE Professional Development Conference, American Society of Safety Engineers, Orlando, FL.

[3] Wei, H., et al. (2010) Synthesis of Unconventional Dynamic Merge Metering Traffic Control for Work Zones. Open Transportation Journal, 4, 52-60. https://doi.org/10.2174/1874447801004010052

[4] Jiang, Y. (1999) Traffic Capacity, Speed, and Queue-Discharge Rate of Indiana's Four-Lane Freeway Work Zones. Transportation Research Record, 1657, 10-17. https://doi.org/10.3141/1657-02

[5] Chitturi, M.V., Benekohal, R.F. and Kaja-Mohideen, A.Z. (2008) Methodology for Computing Delay and User Costs in Work Zones. Transportation Research Record, 2055, 31-38. https://doi.org/10.3141/2055-04

[6] Mallela, J. and Sadavisam, S. (2011) Work Zone Road User Costs: Concepts and Applications (No. FHWA-HOP-12-005). Federal Highway Administration, Washington DC.

[7] McCoy, P.T. and Pesti, G. (2001) Dynamic Late Merge-Control Concept for Work Zones on Rural Interstate Highways. Transportation Research Record, 1745, 20-26. https://doi.org/10.3141/1745-03

[8] Chitturi, M. and Benekohal, R. (2010) Work Zone Queue Length and Delay Me- 
thodology. Transportation Letters, 2, 273-283.

https://doi.org/10.3328/TL.2010.02.04.273-283

[9] Tang, Y. and Chien, S.I.J. (2008) Scheduling Work Zones for Highway Maintenance Projects: Considering a Discrete Time-Cost Relation. Transportation Research Record, 2055, 21-30. https://doi.org/10.3141/2055-03

[10] Kim, T., Lovell, D.J. and Paracha, J. (2001) A New Methodology to Estimate Capacity for Freeway Work Zones. Transportation Research Board, Washington DC.

[11] Sisiopiku, V.P. and Ramadan, O.E. (2017) Evaluation of Traffic Control Options in Work Zones (No. 2016-001). Final Report to the Southeastern Transportation Research, Innovation, Development and Education Center (STRIDE), Birmingham, AL.

[12] Beacher, A.G., Fontaine, M.D. and Garber, N.J. (2005) Field Evaluation of Late Merge Traffic Control in Work Zones. Transportation Research Record, 1911, 33-41. https://doi.org/10.1177/0361198105191100104

[13] Kurker, M., Fournier, C., Zhao, Q., Hakimi, S., Qi, Y., Tang, S. and Machemehl, R. (2014) Minimizing User Delay and Crash Potential through Highway Work Zone Planning (No. FHWA/TX-13/0-6704-1). Texas Department of Transportation, Research and Technology Implementation Office, Austin.

[14] Harb, R., Radwan, E. and Dixit, V.V. (2012) Comparing Three Lane Merging Schemes for Short-Term Work Zones: A Simulation Study. ISRN Civil Engineering. https://doi.org/10.5402/2012/507269

[15] FHWA (2010) Manual on Uniform Traffic Control Devices. 2009 Edition, Claitor's Law Books and Publishing, Baton Rouge, 137-179.

[16] McCoy, P.T., Pesti, G. and Byrd, P.S. (1999) Alternative Driver Information to Alleviate Work-Zone-Related Delays (No. SPR-PL-1 (35) P513).

[17] Ramadan, O.E. and Sisiopiku, V.P. (2018) Modeling Highway Performance under Various Short-Term Work Zone Configurations. ASCE Journal of Transportation Engineering, Part A: Systems, 144, 1-7. https://doi.org/10.1061/JTEPBS.0000176

[18] Pesti, G., Wiles, P., Cheu, R.L.K., Songchitruksa, P., Shelton, J. and Cooner, S. (2008) Traffic Control Strategies for Congested Freeways and Work Zones (No. FHWA/TX-08/0-5326-2). Texas Transportation Institute, College Station.

[19] Benekohal, R.F., Kaja-Mohideen, A.Z. and Chitturi, M.V. (2004) Methodology for Estimating Operating Speed and Capacity in Work Zones. Transportation Research Record, 1883, 103-111. https://doi.org/10.3141/1883-12

[20] Fhwa, U. (2013) Work Zone Operations Best Practices Guidebook (Third Edition). US Department of Transportation, Washington DC.

[21] Nemeth, Z.A. and Rouphail, N.M. (1982) Lane Closures at Freeway Work Zones: Simulation Study. Transportation Research Record, 869, 19-25.

[22] Mousa, R.M., Rouphail, N.M. and Azadivar, F. (1990) Integrating Microscopic Simulation and Optimization: Application to Freeway Work Zone Traffic Control. Transportation Research Record, 1254, 14-25.

[23] Datta, T., Schattler, K.L., Guha, A. and Kar, P. (2004) Development and Evaluation of an Advanced Dynamic Lane Merge Traffic Control System for 3 to 2 Lane Transition Areas in Work Zones (No. Research Report RC-1451). Michigan Department of Transportation, Construction and Technology Division, Lansing.

[24] Beacher, A.G., Fontaine, M.D. and Garber, N.J. (2004) Evaluation of the Late Merge Work Zone Traffic Control Strategy (No. FHWA/VTRC 05-R6). Virginia Transportation Research Council, Charlottesville. 
[25] Tarko, A.P., Kanipakapatnam, S.R. and Wasson, J.S. (1998) Modeling and Optimization of the Indiana Lane Merge Control System on Approaches to Freeway Work Zones, Part I. Joint Transportation Research Program, 345. https://doi.org/10.5703/1288284313469

[26] Ramadan, O.E. and Sisiopiku, V.P. (2015) Bottleneck Merge Control Strategies for Work Zones: Available Options and Current Practices. Open Journal of Civil Engineering, 5, 428. https://doi.org/10.4236/ojce.2015.54043

[27] Chatterjee, I., Edara, P., Menneni, S. and Sun, C. (2009) Replication of Work Zone Capacity Values in a Simulation Model. Transportation Research Record, 2130, 138-148. https://doi.org/10.3141/2130-17

[28] Harb, R. (2009) Safety and Operational Evaluation of Dynamic Lane Merging in Work Zones.

[29] Vaughan, C., Cunningham, P.C., Warchol, P.S., Findley, D., Carnes, C., Sallade, S. and Kearns, B. (2018) The Effects of Late Lane Merges on Travel Times. NCDOT Project 2015-08 Report, FHWA/NC/2015-08.

[30] Kang, K.P., Chang, G.L. and Paracha, J. (2006) Dynamic Late Merge Control at Highway Work Zones: Evaluations, Observations, and Suggestions. Transportation Research Record, 1948, 86-95. https://doi.org/10.1177/0361198106194800110

[31] Grillo, L.F., Datta, T.K. and Hartner, C. (2008) Dynamic Late Lane Merge System at Freeway Construction Work Zones. Transportation Research Record, 2055, 3-10. https://doi.org/10.3141/2055-01

[32] Saha, T. (2019) Enhancing Work Zone Mobility through Design and Control of Lane Closures. Master's Thesis, The University of Alabama, Birmingham.

[33] Weng, J. and Meng, Q. (2012) Ensemble Tree Approach to Estimating Work Zone Capacity. Transportation Research Record, 2286, 56-67. https://doi.org/10.3141/2286-07

[34] Barua, L., Zou, B., Noruzoliaee, M. and Derrible, S. (2019) Predicting Airport Runway and Taxiway Pavement Conditions: A Gradient Boosting Approach (No. 19-05803). 